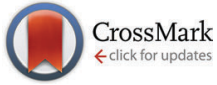

Cite this: Chem. Commun., 2015, 51,4383

Received 15th December 2014 Accepted 3rd February 2015

DOI: $10.1039 / \mathrm{c} 4 \mathrm{cc} 09987 \mathrm{~g}$

www.rsc.org/chemcomm

\section{Visible light promoted thiol-ene reactions using titanium dioxide $\dagger$}

\author{
Venugopal T. Bhat, Petar A. Duspara, Sangwon Seo, Nor Syazwani Binti Abu Bakar \\ and Michael F. Greaney*
}

The radical addition of thiols to alkenes is reported under photoredox conditions, using visible light and $\mathrm{TiO}_{2}$ as a cheap and readily available photocatalyst.

Recent developments in visible light photoredox catalysis (PRC) have substantially expanded the scope and application of organic photochemistry. ${ }^{1}$ Using a domestic lightbulb as the light source, rather than specialist UV equipment, the process uses a photoactive catalyst to mediate electron transfer between reactants, resulting in novel transformations that frequently proceed under mild conditions. The vast majority of PRC in organic synthesis to date is based on two classes of catalyst; transition metal complexes, such as the archetypal $\mathrm{Ru}(\mathrm{bpy})_{3} \mathrm{Cl}_{2}$ and $\mathrm{Ir}(\mathrm{ppy})_{3}$ systems, or organic dyes such as methylene blue or eosin-Y. The Noble metals of the first class are expensive and a limited resource, but are highly optimisable in terms of ligand-metal tuning. Organic dyes lack this particular quality, but may be tuned via conventional synthesis and are usually less expensive. We were interested in exploiting a third class of photoredox catalyst; semi-conducting metal oxides such as titania $\left(\mathrm{TiO}_{2}\right)$. With 4 million tons of titania being produced per annum, the material is cheap, readily accessible, and non-toxic (commonly ingested as food additive E 171), as well as offering the process benefits of heterogeneous catalysis such as simple removal by filtration. ${ }^{2}$ The UV photoredox properties of $\mathrm{TiO}_{2}$ have been extensively investigated and applied on an industrial scale to areas such as water treatment and photovoltaics. Applications to organic synthesis, however, remain under-developed, particularly in the area of visible light photochemistry. ${ }^{3,4}$ We were interested in developing a titania-mediated PRC reaction using visible light, and chose to investigate the thiol-ene reaction for this purpose.

The addition of thiols to alkenes is a radical reaction that is typically initiated with UV light. ${ }^{5}$ Although an old reaction, ${ }^{6}$ its

School of Chemistry, University of Manchester, Oxford Rd, Manchester, M13 9PL, UK. E-mail: michaelgreaney@manchester.ac.uk

$\dagger$ Electronic supplementary information (ESI) available: Synthesis and characterisation data for all new compounds. See DOI: 10.1039/c4cc09987g reliability, substrate scope, and compatibility has led to renewed interest in the context of click chemistry, where the facile $\mathrm{C}-\mathrm{S}$ bond formation can be used as a powerful ligation strategy in biological and materials science. ${ }^{7}$ Indeed, the largest field of application for thiol-ene chemistry is currently in polymer science, where thiols are cross-linked with alkenes under UV curing conditions, producing polymers with very uniform step-growth properties. ${ }^{8}$ Recent literature reports have established PRC for thiol-ene addition using both $\mathrm{Ru}(\mathrm{II})$ and eosin-Y photocatalysis, providing an important frame of reference for our inchoate titania process. ${ }^{9-11}$

We were aware at the outset that titania visible light PRC would likely require a nanoparticulate form of the catalyst. Unmodified titania absorbs very weakly in the visible region, but there is evidence that substrate binding to the surface can shift the absorption and enable electron transfer. ${ }^{4 a, c-e}$ Rueping and co-workers, for example, have recently demonstrated

Table 1 Titania PRC of the thiol-ene reaction ${ }^{a}$

\begin{tabular}{lllll}
\hline & & & & \\
Entry & $\mathrm{TiO}_{2}$ (equiv.) & Solvent & Light source & Yield $^{b}(\%)$ \\
\hline 1 & 1.0 & $\mathrm{MeCN}$ & $20 \mathrm{~W}$ light & $98\left(96^{c}\right)$ \\
2 & 1.0 & $\mathrm{DCM}$ & $20 \mathrm{~W}$ light & 96 \\
3 & 1.0 & - & $20 \mathrm{~W}$ light & 97 \\
4 & 1.0 & $\mathrm{MeCN}$ & Blue LED & 80 \\
$5^{d}$ & 1.0 & $\mathrm{MeCN}$ & No light & 0 \\
$6^{e}$ & 0 & $\mathrm{MeCN}$ & $20 \mathrm{~W}$ light & 20 \\
7 & 0 & $\mathrm{MeCN}$ & $\mathrm{Blue}$ LED & 0 \\
8 & 0.5 & $\mathrm{MeCN}$ & $20 \mathrm{~W}$ light & 88 \\
9 & 0.1 & $\mathrm{MeCN}$ & $20 \mathrm{~W}$ light & 82 \\
$10^{e}$ & 0.1 & $\mathrm{MeCN}$ & $20 \mathrm{~W}$ light & 92 \\
$11^{f}$ & 1.0 & $\mathrm{MeCN}$ & $20 \mathrm{~W}$ light & 50 \\
$12^{g}$ & 1.0 & $\mathrm{MeCN}$ & $20 \mathrm{~W}$ light & 84
\end{tabular}

${ }^{a}$ Cyclohexene (1.0 mmol), benzyl mercaptan ( $\left.4.0 \mathrm{mmol}\right)$, titania $\left(\mathrm{TiO}_{2} \mathrm{P} 25\right)$ and solvent $(1.0 \mathrm{~mL})$ at room temperature for $16 \mathrm{~h}$; light source placed 10-15 cm away from reaction vials. ${ }^{b}$ Yields determined by ${ }^{1} \mathrm{H}$ NMR using nitromethane as the internal standard. ${ }^{c}$ Isolated yields. ${ }^{d}$ Foil-wrapped flask for $16 \mathrm{~h} .{ }^{e}$ Reaction for $40 \mathrm{~h} .{ }^{f}$ Using degassed MeCN under $\mathrm{N}_{2}$ atmosphere. ${ }^{g}$ Using $2.5 \mathrm{mmol}$ of benzyl mercaptan. 
visible light photoredox activity in dehydrogenative coupling reactions using commercially available titania P25 nanoparticles, ${ }^{4 d, e}$ and we chose to begin our studies using this material (aeroxide ${ }^{\mathbb{R}}$ from Sigma-Aldrich). Using the addition of benzyl mercaptan (1a) to cyclohexene (2a) as a test reaction, we were pleased to observe very high conversions into adduct 3a using one equivalent of $\mathrm{TiO}_{2}$ in MeCN under irradiation with a domestic light bulb (Table 1). The reaction was also viable in DCM (entry 2), under neat conditions (entry 3), and using blue LEDs as an alternative light source (entry 4).

Control experiments established that titania in the dark gave no reaction (entry 5), but there was a small background reaction with ambient light in the absence of titania (20\% conversion). We were pleased to see that the titania loading could be

Table 2 Scope of alkene coupling partners ${ }^{a}$

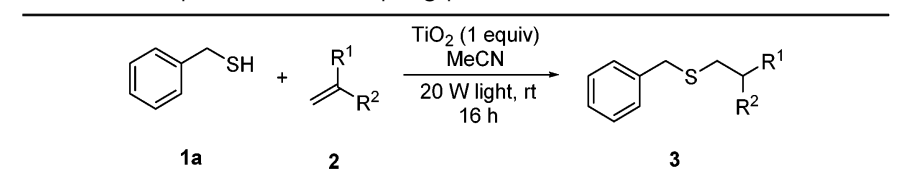

\begin{tabular}{|c|c|c|c|}
\hline & 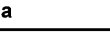 & & \\
\hline Entry & Alkene & Product & Yield $^{b}(\%)$ \\
\hline
\end{tabular}

2

$2 b$<smiles>CC(=O)OCCCSCc1ccccc1</smiles>

$2 c$

$3 c$<smiles>C=CC(O)O</smiles><smiles>[M]C(O)CCSCc1ccccc1</smiles>

$78(12)$

3

2d

4<smiles>C=C(C)C(=C)O</smiles><smiles>[M]C(CO)CSCc1ccccc1</smiles>

$89(68)$

5<smiles>C=CC[As]</smiles><smiles>CCCCSCc1ccccc1</smiles>

$2 f$<smiles></smiles><smiles>N#CCCSCc1ccccc1</smiles>

6 $2 \mathrm{~g}$

7<smiles>C=COC(C)=O</smiles><smiles>CC(=O)OCCSCc1ccccc1</smiles>

$80(0)$

$98(90)$<smiles>C=Cc1ccccc1</smiles><smiles>c1ccc(CCSCc2ccccc2)cc1</smiles>

$3 i$<smiles>C=Cc1ccc(C)cc1</smiles><smiles>Cc1ccc(CCSCc2ccccc2)cc1</smiles>

$98(93)$

9

10<smiles>C=Cc1ccc(Cl)cc1</smiles><smiles>Clc1ccc(CCSCc2ccccc2)cc1</smiles>

$95(30)$

reduced to catalytic quantities with little drop in overall yield (entries 8-10), and we established that oxygen was beneficial for the reaction. Use of an inert atmosphere and de-gassed solvent halved the efficiency of the process (entry 11). This was an expected requirement, as an oxidative quencher is needed to balance charge and prevent hole-electron recombination in the titania photocatalyst (vide infra).

With a titania PRC system in place, we moved on to investigate substrate scope, beginning with the alkene partner. We were pleased to find that a variety of primary and 1,1-disubstituted substrates underwent successful thiol-ene reaction with benzyl mercaptan (Table 2). The reaction was tolerant of a variety of functional groups (ester, alcohol, silane, nitrile, halogen) giving the thiol ene adducts 3 in generally high yields. Substitution was

Table 3 Catalytic thiol-ene - thiol scope $e^{a, b}$

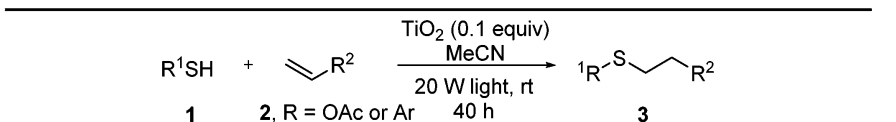

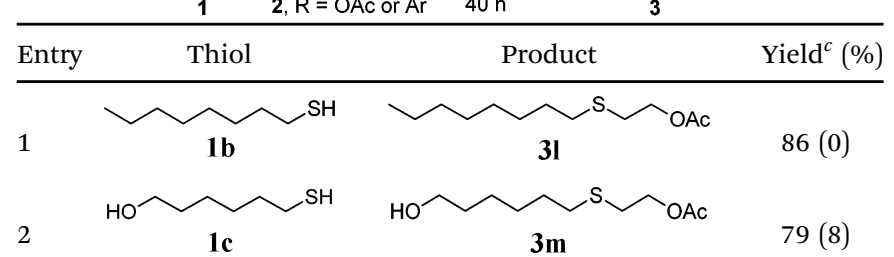

3<smiles>COC(=O)CCS</smiles><smiles>COC(=O)CCSCCOC(C)=O</smiles>

4<smiles>Sc1ccccc1</smiles>

1e

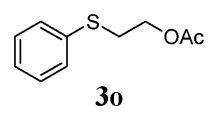<smiles>CC(=O)OCCSC1CCCCC1</smiles>

$3 p$

$1 f$<smiles>CC(C)(C)S</smiles><smiles>SCCS</smiles>

$1 \mathrm{~h}$<smiles>c1ccc(CCSCCSCCSCc2ccccc2)cc1</smiles>

7

8<smiles>[Li]CCS</smiles><smiles>Cc1ccc(CCSCCSCCc2ccc([N+](=O)[O-])cc2)cc1</smiles><smiles>SCCC[Tl]</smiles><smiles>Cc1ccc(CCSCCCSCCc2ccc([N+](=O)[O-])cc2)cc1</smiles>

$3 s$<smiles>SCCS</smiles><smiles>COc1ccc(CCSCCSCCc2ccc(OC)cc2)cc1</smiles>

$3 t$
${ }^{a}$ Thiol $(4.0 \mathrm{mmol})$, vinyl acetate $(1.0 \mathrm{mmol})$, titania $\left(\mathrm{TiO}_{2} \mathrm{P} 25\right.$, $0.1 \mathrm{mmol})$ and MeCN $(1.0 \mathrm{~mL})$ at room temperature for $16-40 \mathrm{~h}$; light source placed $10-15 \mathrm{~cm}$ away from reaction vials. ${ }^{b}$ Dithiol $(1 \mathrm{mmol})$, styrene $(4 \mathrm{mmol})$ and conditions as previous. ${ }^{c}$ Isolated yields; numbers in parentheses are the yield obtained under standard reaction conditions where titanium dioxide is absent. ${ }^{d} 1$ equiv. of titania used. 


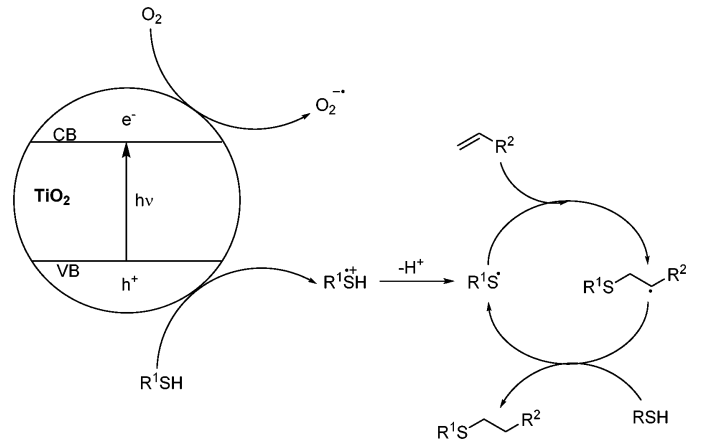

Scheme 1 Mechanistic pathway for titania thiol-ene reaction.

tolerated at the 2- and 3-positions of the alkene (entries 3 and 4), but 1,2-disubstitution was restricted to cyclic alkenes. Vinyl acetate and acrylonitrile were both productive, interestingly undergoing no reaction at all in the absence of PRC (entries 6 and 7). More reactive alkenes such as styrenes gave very high yields of the thiol ene products, but background reaction was high for $2 \mathbf{i}$ and $2 \mathbf{j}$.

Thiol scope was initially trialled (Table 3) using catalytic amounts of titania ( 0.1 equiv.) and vinyl acetate $(\mathbf{2 h})$, an alkene with zero background reaction for the addition of benzyl mercaptan (Table 1, entry 7 ). We were pleased to find that the catalytic protocol was successful, with primary alkyl thiols (entries 1-3) and thiophenols (entry 4) undergoing thiol-ene reaction under the longer reaction time of $40 \mathrm{~h}$. Increasing steric hindrance around the thiol was deleterious, with cyclohexyl thiol reacting in moderate yield (entry 5) and tert-butyl thiol undergoing no reaction, even with stoichiometric titania (entry 6). We could extend the reaction to a double thiol-ene reaction, with ethane and propane dithiol undergoing addition to styrenes in good yield (entries 7-9). $p$-Methoxystyrene proved less reactive, and required stoichiometric quantities of titania to yield $3 \mathbf{t}$ in an acceptable timeframe.

A mechanism for the reaction is outlined in Scheme 1, based upon the photo-excitation of electrons to the conduction band of the titania catalyst. The resultant holes are reductively quenched by the thiol, generating a thiyl radical cation, which can lose a proton to give a thiyl radical. Oxygen acts as a sacrificial electron acceptor, enhancing reaction efficiency by reducing hole-electron recombination in the titania. The thiyl radical can then initiate the thiol-ene cycle through addition to an alkene and generation of an alkyl radical, which propagates the reaction by abstracting a hydrogen atom from the thiol starting material.

In conclusion, we have developed a titania photoredox system for the thiol-ene reaction that uses visible light. The photocatalyst is cheap, robust, readily available, and easily processed out of the reaction for re-use. Applications of this method to the broad remit of thiol-ene chemistry are ongoing in our laboratory.

We thank the University of Manchester and the EPSRC for funding.

\section{Notes and references}

1 Recent reviews: (a) J. M. R. Narayanam and C. R. J. Stephenson, Chem. Soc. Rev., 2011, 40, 102-113; (b) C. K. Prier, D. A. Rankic and D. W. C. MacMillan, Chem. Rev., 2013, 113, 5322-5363; (c) S. Fukuzumi and K. Ohkubo, Org. Biomol. Chem., 2014, 12, 6059-6071; (d) D. P. Hari and B. König, Chem. Commun., 2014, 50, 6688-6699; (e) M. N. Hopkinson, B. Sahoo, J. L. Li and F. Glorius, Chem. - Eur. J., 2014, 20, 3874-3886; $(f)$ D. A. Nicewicz and T. M. Nguyen, ACS Catal., 2014, 4, 355-360.

2 (a) C. Chen, W. Ma and J. Zhao, Chem. Soc. Rev., 2010, 39, 4206-4219; (b) P. Roy, S. Berger and P. Schmuki, Angew. Chem., Int. Ed., 2011, 50, 2904-2939; (c) B. O'Regan and M. Grätzel, Nature, 1991, 353, 737-740.

3 Selected examples of UV titania photoredox catalysis: $(a)$ C. M. Wang and T. E. Mallouk, J. Am. Chem. Soc., 1990, 112, 2016-2018; (b) C. W. Lai and T. E. Mallouk, Chem. Commun., 1993, 1359-1361; (c) S. Higashida, A. Harada, R. Kawakatsu, N. Fujiwara and M. Matsumura, Chem. Commun., 2006, 2804-2806; (d) X. J. Lang, H. W. Ji, C. C. Chen, W. H. Ma and J. C. Zhao, Angew. Chem., Int. Ed., 2011, 50, 3934-3937; (e) D. W. Manley, R. T. McBurney, P. Miller, R. F. Howe, S. Rhydderch and J. C. Walton, J. Am. Chem. Soc., 2012, 134, 13580-13583; $(f)$ D. W. Manley, R. T. McBurney, P. Miller and J. C. Walton, J. Org. Chem., 2014, 79, 1386-1398; $(g)$ D. W. Manley and J. C. Walton, Org. Lett., 2014, 16, 5394-5397.

4 With visible light: (a) F. Parrino, A. Ramakrishnan and H. Kisch, Angew. Chem., Int. Ed., 2008, 47, 7107-7109; (b) M. Cherevatskaya, M. Neumann, S. Fuldner, C. Harlander, S. Kummel, S. Dankesreiter, A. Pfitzner, K. Zeitler and B. König, Angew. Chem., Int. Ed., 2012, 51, 4062-4066; (c) X. Lang, W. Ma, Y. Zhao, C. Chen, H. Ji and J. Zhao, Chem. - Eur. J., 2012, 18, 2624-2631; (d) M. Rueping, J. Zoller, D. C. Fabry, K. Poscharny, R. M. Koenigs, T. E. Weirich and J. Mayer, Chem. - Eur. J., 2012, 18, 3478-3481; (e) C. Vila and M. Rueping, Green Chem., 2013, 15, 2056-2059; $(f)$ C. D. McTiernan, S. P. Pitre, H. Ismaili and J. C. Scaiano, Adv. Synth. Catal., 2014, 356, 2819-2824.

5 F. Dénès, M. Pichowicz, G. Povie and P. Renaud, Chem. Rev., 2014, 114, 2587-2693.

6 T. Posner, Ber. Dtsch. Chem. Ges., 1905, 38, 646-657.

7 C. E. Hoyle and C. N. Bowman, Angew. Chem., Int. Ed., 2010, 49, 1540-1573.

8 (a) A. B. Lowe, Polym. Chem., 2014, 5, 4820-4870; (b) N. Brummelhuis, C. Diehl and H. Schlaad, Macromolecules, 2008, 41, 9946-9947; and references therein.

9 (a) E. L. Tyson, M. S. Ament and T. P. Yoon, J. Org. Chem., 2013, 78, 2046-2050; (b) E. L. Tyson, Z. L. Niemeyer and T. P. Yoon, J. Org. Chem., 2014, 79, 1427-1436.

10 M. H. Keylor, J. E. Park, C.-J. Wallentin and C. R. J. Stephenson, Tetrahedron, 2014, 70, 4264-4269.

11 (a) C. A. DeForest and K. S. Anseth, Nat. Chem., 2011, 3, 925-931; (b) C. A. DeForest and K. S. Anseth, Angew. Chem., Int. Ed., 2012, 51, 1816-1819; (c) H. Shih and C. C. Lin, Macromol. Rapid Commun., 2013, 34, 269-273; (d) H. Shih, A. K. Fraser and C. C. Lin, ACS Appl. Mater. Interfaces, 2013, 5, 1673-1680. 